\title{
Espécies frutíferas na arborização urbana do município de Santarém, Pará
}

A silvicultura urbana compreende todas as atividades relacionadas a implantação e manejo da vegetação presente nas cidades, podendo ocorrer nos espaço verdes públicos ou privados e proporciona diversos benefícios socioambientais. O objetivo do trabalho foi identificar a ocorrência de espécies frutíferas utilizadas na alimentação de seres humanos e avifauna em 4 bairros e 11 praças do município de Santarém, Pará, através do inventário total destas áreas, considerando somente os indivíduos com altura igual ou superior a 1,5m. Foram calculadas a Frequência absoluta (FR) e Frequência relativa (FR) de cada espécie alimentar em relação ao número total de indivíduos inventariados. Quanto à origem das espécies, foram classificadas como exóticas ou nativas. Além disso, utilizando o método de revisão de literatura, foram apontadas características acerca do tamanho e peso dos frutos. Foram contabilizados 1646 indivíduos arbóreos, distribuídos em 63 espécies de 31 famílias botânicas. Sendo classificadas como frutíferas de capacidade alimentícia para humanos e/ou avifauna 660 indivíduos, de 22 espécies pertencentes a 10 famílias, com destaque para a Mangueira (Mangifera indica L.), Oitizeiro (Licania tomentosa), Jambeiro (Syzygium malaccense), Castanhola (Terminalia catappa), Cajueiro (Anacardium occidentale) e Goiabeira (Psidium guajava) com maior número de representantes. Desta forma, é possível afirmar que a arborização no município de Santarém é composta por 40,09\% de espécies frutíferas alimentares à população e avifauna local.

Palavras-chave: Alimentícias; Avifauna; Silvicultura urbana.

\section{Fruit species in the urban arborization of the city of Santarém, Pará}

Urban arborization incorporates all activities related to the implantation and management of vegetation present in cities, which may occur in public or private green spaces and provides several social and environmental benefits. The objective of this work was to identify the occurrence of fruit species used in the feeding of humans and avifauna in 4 districts and 11 squares of the municipality of Santarém, Pará, through a total inventory of these areas, considering only individuals with a height equal to or greater than $1.5 \mathrm{~m}$. The Absolute Frequency $(\mathrm{Fa})$ and Relative Frequency of each food species were calculated in relation to the total number of individuals inventoried. Regarding the origin of the species, they were classified as exotic or native. In addition, using the literature review method, characteristics about fruit size and weight were pointed out. A total of 1646 arboreal individuals were recorded, distributed in 63 species of 31 botanical families. A total of 660 individuals were classified as fruiting with human and / or avifauna feeding capacity. Of 22 species belonging to 10 families, Mangueira (Mangifera indica L.), Oitizeiro (Licania tomentosa), Jambeiro (Syzygium malaccense), Castanhola (Terminalia catappa), Cajueiro (Anacardium occidentale) and Goiabeira (Psidium guajava) with the highest number of representatives. In this way, it is possible to affirm that the arborization in the municipality of Santarém is composed of $40.09 \%$ of fruit species fed to the population and local bird fauna.

Keywords: Food; Avifauna; Urban forestry.

Livia Karine Lima Rabelo

Universidade Federal do Oeste do Pará, Brasil http://lattes.cnpq.br/2513116920954057 liviarabello16@gmail.com

\section{Eldeane de Castro Pires}

Universidade Federal do Oeste do Pará, Brasil http://lattes.cnpq.br/4200887834787118 eldeanecastro@gmail.com

Sarah Stephanie Rebelo Traian Baumann Universidade Federal do Oeste do Pará, Brasil http://lattes.cnpq.br/7722661512593219 sarah.engflor@gmail.com
Camila Amorim Santa Brígida (iD

Universidade Federal do Oeste do Pará, Brasil http://lattes.cnpq.br/7618034411950250

http://orcid.org/0000-0003-1229-7422

brigida88camila@gmail.com

Jaine Beatriz Sousa da Silva

Universidade Federal do Oeste do Pará, Brasil http://lattes.cnpq.br/0914434709092709 jainebeatrizsousadasilva11@gmail.com

\section{Pricila da Silva Lima}

Universidade Federal do Oeste do Pará, Brasil http://lattes.cnpq.br/0233912900535413 pricila.bibi.7@gmail.com
Mayra Piloni Maestri ib

Universidade Federal Rural da Amazônia, Brasil http://lattes.cnpq.br/2687102042811310 http://orcid.org/0000-0002-8936-952X mayrapmaestri@hotmail.com

Marina Gabriela Cardoso de Aquino (iD Universidade Federal do Oeste do Pará, Brasil http://lattes.cnpq.br/2168843028631934 http://orcid.org/0000-0002-0160-0804 marinaacardosoo@gmail.com
Referencing this:

RABELO, L. K.; PIRES, E. C.; BAUMANN, S. S. R. T.; BRÍGIDA, C. A. S.; SILVA, J. B. S.; LIMA, P. S.; MAESTRI, M. P.; AQUINO, M. G. C.. Espécies frutíferas na arborização urbana do município de Santarém, Pará. Revista Ibero Americana de Ciências Ambientais, v.10, n.3, p.335341, 2019. DOI: http://doi.org/10.6008/CBPC21796858.2019.003.0028 


\section{INTRODUÇÃO}

Silvicultura urbana é uma área da Engenharia Florestal que compreende todas as atividades relacionadas a implantação e manejo da vegetação presente nas cidades, podendo ocorrer nos espaços verdes públicos ou privados como os bosques, parques, praças, jardins, ruas e calçadas (RODRIGUES, 2002). Ela proporciona benefícios socioambientais, arborizar uma cidade pode prover melhoria na qualidade do ar, amenização de temperaturas, aumento da umidade, permeabilidade e fertilidade do solo, amortecimento da velocidade dos ventos, abrigo e alimentação para população humana e fauna existente, além da redução do estresse psicológico e ruídos sonoros (GOMES et al., 2003; ROSSATTO et al., 2008).

Ribeiro (2009) ressalta que, embora sejam inúmeros os benefícios proporcionados pelo verde nas cidades, o manejo da floresta urbana deve ser realizado através de um planejamento minucioso, a fim de que situações adversas sejam minimizadas, como a perda de diversidade biológica apontada por Biondi et al. (2008), uso excessivo de espécies exóticas devido à falta de conhecimento sobre o potencial da flora brasileira (SILVA et al., 2010) e conflito entre elementos naturais e urbanísticos (sistema elétrico, abastecimento de água, sinalização, calçadas, edificações) tendem a reduzir a eficácia do estabelecimento de espaços verdes (VELASCO et al., 2006; PIRES et al., 2010).

Para tanto, a realização de um inventário florestal quali-quantitativo torna-se instrumento indispensável na compreensão da vegetação urbana, orientando na escolha das espécies mais adequadas ao espaço físico na qual será inserida, execução de tratamentos silviculturais e fitossanitários (MELO et al., 2007). Diante do contexto apresentado, o objetivo deste trabalho foi identificar a ocorrência de espécies frutíferas utilizadas na alimentação de seres humanos e avifauna no município de Santarém, Pará.

\section{REVISÃO TEÓRICA}

O conhecimento de algumas características é imprescindível na escolha das espécies para serem utilizadas na arborização urbana, tais como: resistência ao ataque de microrganismos; copa frondosa e perenifólia para promover sombreamento durante todo o ano; flores com odores e cores variadas; frutos que tenham atrativos para a fauna, alimentação humana, princípios medicinais e/ou geração de renda; folhas grandes para evitar o entupimento de tubulações; fuste com crescimento retilíneo e ausente de espinhos e acúleos; raízes pivotantes e com ausência de sapopemas (NASCIMENTO et al., 2015).

Ao se tratar da utilização de espécies frutíferas ainda é polêmico o assunto entre profissionais do ramo devido a discordância entre os estudiosos. Pois, embora mantenha efeito ornamental, os frutos carnosos e pesados podem cair sobre as calçadas e pedestres, ocasionando acidentes e sujeira, além de, atrair pequenos animais vetores de doenças (CARVALHO et al., 2010).

Desta maneira, Lira Filho et al. (2006) afirmam que o paisagismo urbano deve priorizar a utilização de espécies nativas que produzam frutos pequenos, pois servem de abrigo, descanso e fonte de alimentação para as aves silvestres. Quanto às que geram frutos grandes e saborosos como a mangueira, jambeiro e coqueiro, uma solução seria plantá-las em praças ou ambientes onde seja possível vedar o trafego de pessoas 
e veículos em baixo da árvore (CARVALHO et al., 2010).

\section{MATERIAIS E MÉTODOS}

\section{Área de estudo}

O estudo foi realizado na cidade de Santarém, município situado na região Oeste do Pará, entre as coordenadas geográficas $2^{\circ} 26^{\prime} 22^{\prime \prime} \mathrm{S}$ e $54^{\circ} 41^{\prime} 55^{\prime \prime} \mathrm{O}$, com uma extensão territorial de $17.898 \mathrm{~km}^{2}$ e, aproximadamente, 302.667 mil habitantes (IBGE, 2019). O clima dominante da região é quente e úmido, característico das florestas tropicais, com temperatura média anual variando de $25 \circ$ a 28 ㄷ $\mathrm{C}$ umidade relativa média do ar de 86\% (SANTARÉM, 2018).

A avaliação da ocorrência de espécies frutíferas concentrou-se em 4 bairros (Aparecida, Centro, Jardim Santarém e Santa Clara) e 11 praças (Barão de Santarém, das Flores, Liberdade, Matriz, Menino Jesus, Mirante, Nossa Senhora das Graças, Parque da Cidade, Pescado, Rodrigues dos Santos e São Sebastião) do município de Santarém, cuja localização estão apresentadas na figura 1.
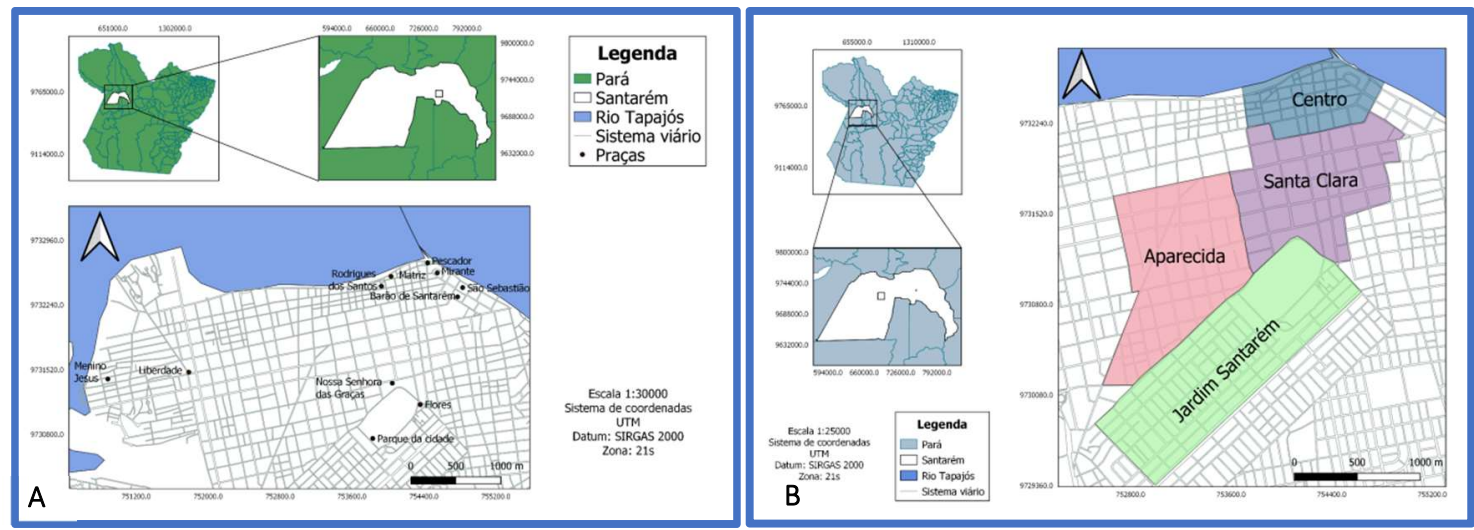

Figura 1: A. Mapa de localização dos bairros B. Praças estudadas.

\section{Coleta e análise de dados}

O censo florístico foi realizado nos meses de novembro a dezembro de 2017 nas ruas e nos meses de novembro a dezembro de 2018 nas praças, onde foram coletados os seguintes dados: nome da espécie, diâmetro a 1,3m do solo (DAP), altura (h), diâmetro de copa, fenologia, fitossanidade, origem e a caracterização dos frutos com base na observação e revisão de literatura. Foram medidos todos os indivíduos com altura $\geq 1,5 \mathrm{~m}$.

Além disso, registros fotográficos de todas as árvores inventariadas foram realizados para auxiliar na identificação botânica das espécies, além da consulta às literaturas especializadas, como Lorenzi et al. (2001) e Lorenzi (2002). Para atualização da grafia dos táxons foi utilizado o sistema Taxonomic Name Resolution Service (BOYLE et al., 2013) e o sistema de classificação APG IV foi adotado (BYNG et al., 2016). O cálculo de frequência relativa foi realizado utilizando a seguinte fórmula:

$$
\mathrm{FR}=\frac{n^{\mathrm{o}} \text { de indivíduos }}{n^{\mathrm{o}} \text { de indivíduos total }} \times 100
$$

Quanto à origem das espécies, consideraram-se nativas aquelas originárias de formações vegetais 
ocorrentes no Brasil. As espécies que ocorrem em outros ecossistemas diferentes dos que aparecem em território brasileiro, foram consideradas exóticas, método adaptado de Paula et al. (2015). A tabulação e análise dos dados foram realizadas em planilhas eletrônicas.

\section{RESULTADOS}

A partir do inventário quali-quantitativo foram contabilizados 1646 indivíduos arbóreos, distribuídos em 63 espécies de 31 famílias botânicas. Sendo classificadas como frutíferas de capacidade alimentícia para humanos e/ou avifauna 660 indivíduos, de 22 espécies pertencentes a 10 famílias. Quanto à origem das espécies frutíferas, que podem ser utilizadas na alimentação humana e da avifauna, 14 espécies são classificadas como nativas (275 indivíduos) e 8 espécies como exóticas (385 indivíduos).

As espécies que apresentaram maior ocorrência foram Mangueira (Mangifera indica L.), Oitizeiro (Licania tomentosa), Jambeiro (Syzygium malaccense), Castanhola (Terminalia catappa), Cajueiro (Anacardium occidentale) e Goiabeira (Psidium guajava). As demais espécies são encontradas em menores números de representatividade conforme apresentado na tabela 1.

Tabela 1: Lista de espécies frutíferas alimentares inventariadas na arborização da cidade. Onde: FA: frequência absoluta e FR: frequência relativa.

\begin{tabular}{|l|l|l|l|l|l|}
\hline Nome Científico & Nome Vulgar & Família & Origem & FA & FR (\%) \\
\hline Anacardium occidentale & Caju & Anacardiaceae & Nativa & 30 & 1,8 \\
\hline Anacardium spruceanum & Cajuaçu ou cajuí da mata & Anacardiaceae & Nativa & 1 & 0,06 \\
\hline Annona squamosa & Ata & Annonaceae & Nativa & 2 & 0,12 \\
\hline Bactris gasipaes & Pupunha & Arecaceae & Nativa & 1 & 0,06 \\
\hline Byrsonima sericea & Muruci & Malpighiaceae & Nativa & 4 & 0,24 \\
\hline Cassia fistula & Cacho-de-ouro & Fabaceae & Exótica & 2 & 0,12 \\
\hline Citrus aurantium & Laranja da terra & Rutaceae & Exótica & 1 & 0,06 \\
\hline Citrus limon & Limão & Rutaceae & Exótica & 2 & 0,12 \\
\hline Cocos nucifera & Côco & Arecaceae & Exótica & 7 & 0,42 \\
\hline Dipteryx odorata & Fabaceae & Nativa & 1 & 0,06 \\
\hline Euggenia uniflora & Cumaru & Myrtaceae & Nativa & 1 & 0,06 \\
\hline Inga edulis & Ginga ou Pitanga & Fabaceae & Nativa & 1 & 0,06 \\
\hline Licania tomentosa & Chrysobalanaceae & Nativa & 207 & 12,5 \\
\hline Malpighia glabra & Ingá- cipó & Malpighiaceae & Nativa & 2 & 0,12 \\
\hline Mangifera indica L. & Aiti & Anacardiaceae & Exótica & 249 & 15 \\
\hline Mauritia flexuosa & Manga & Nativa & 1 & 0,06 \\
\hline Murraya paniculata & Arecaceae & Exótica & 1 & 0,06 \\
\hline Psidium guajava & Rutaceae & Nativa & 20 & 1,2 \\
\hline Syzygium malaccense & Murtaceae & Exótica & 89 & 5,1 \\
\hline Spondias mombin & Goiaba & Myrtaceae & Nativa & 2 & 0,12 \\
\hline Talisia esculenta & Jambo & Anacardiaceae & Nativa & 2 & 0,12 \\
\hline Terminalia catappa & Taperebá & Sapindaceae & Combretica & 34 & 2 \\
\hline
\end{tabular}

\section{DISCUSSÃO}

\section{Fitogeografia}

A frequente utilização de espécies exóticas que vem ocorrendo na arborização urbana do município é bastante característica na região central de Horizontina/RS de acordo com a avaliação realizada por Silva et al. (2007) em que, segundo eles, tende a uniformizar a paisagem além de ser considerada a segunda maior ameaça a biodiversidade, perdendo apenas para a destruição antrópica direta.

Em São Gabriel/RS, Teixeira (2016) realizaram uma análise fitossociológica no centro histórico da 
cidade e constataram que o número de espécies exóticas foi de $67 \%$ e o de nativas $33 \%$. Corroborado por Oliveira et al. (2017), que ao inventariarem os indivíduos arbóreos das praças e ruas de Aldeias Altas/MA, concluíram que $80 \%$ das espécies eram exóticas. Dessa forma, nota-se que a predominância de espécies arbóreas exóticas na arborização das cidades é um fato observado em todo o Brasil.

\section{Frequência}

O levantamento florístico mostrou alta representatividade na arborização da cidade de Santarém por mangueira com 249 indivíduos (37,73\%). Esta preferência é perceptível nos diversos municípios localizados no estado do Pará bem como nos bairros da cidade de Belém, conforme apresentado por Batista et al. (2015) e explicada por Loureiro et al. (2010) devido a amplitude de sua copa que proporciona sombreamento e seu fruto utilizado como fonte de renda temporária no período de safra e alimentação tanto para a população quanto para avifauna.

Com a segunda maior frequência encontra-se o oitizeiro com 207 indivíduos (31,36\%) fazendo parte da dominância observada, também, por Paiva et al. (2010) no município de Rio Branco/AC. Segundo Basso et al. (2014), a utilização dessa espécie se dá em razão da redução de temperaturas superficiais ocasionada por sua copa frondosa. Em seguida, o jambeiro com 89 representantes $(13,48 \%)$, embora esteja fora do padrão de uso recomendado por ser parcialmente responsável pelos serviços de reparo técnico e podas na silvicultura urbana (CASTRO et al., 2013).

O somatório de 34 castanholas (5,15\%) encontradas nos bairros e praças de Santarém, assemelhase ao total de 36 indivíduos apresentado no estudo de Stranghetti et al. (2010) que, de acordo com estes autores, trata-se de uma das principais espécies responsáveis pelo comprometimento de calçadas em virtude do desenvolvimento das raízes adventícias.

Assim como no trabalho realizado por Parry (2012) no município de Altamira, durante a análise dos dados, constatou-se a preferência e possível participação direta da população no processo de plantio de espécie frutíferas como o cajueiro com 30 (4,55 \%) e a goiabeira com 20 (3,03\%), ainda que essas espécies possuam características morfológicas indesejáveis para o plantio em praças e vias públicas por fatores como o tamanho dos frutos e a sujeira causada por eles.

De acordo com a literatura, está elevada expressão de poucas espécies reflete na biodiversidade urbana local de maneira que não se recomenda que as espécies utilizadas ultrapassem $30 \%$ de uma mesma família botânica, $20 \%$ de um único gênero e 10\% de uma espécie exclusiva (CEMIG, 2011). No entanto, Serpa et al. (2009) afirmam que tal a predominância ocorre devido a facilidade na produção de mudas e obtenção de sementes.

\section{Características dos frutos}

Muitos são os benefícios proporcionados para a população e aves locais, obtidos através do plantio de espécies frutíferas na arborização urbana visto que, os frutos produzidos por elas podem ser consumidos in natura ou após passarem por algum tipo de processamento. No entanto, a relação entre o peso e tamanho 
dos frutos pode implicar em perdas estéticas e financeiras. Nota-se que espécies como a Acerola, Buriti, Cacho-de-ouro, Cumaru, Ginja ou Pitanga, Murta de jardim, Muruci, Pitomba, Pupunha e Taperebá são pouco utilizadas, embora possuam potencial para o plantio em vias públicas por produzirem frutos pequenos, como mostrado na tabela 2.

Tabela 2: Peso e tamanho médio dos frutos produzidos pelas espécies.

\begin{tabular}{|l|l|l|l|}
\hline & Peso $\mathbf{( g )}$ & Tamanho $(\mathbf{c m})$ & Espécies \\
\hline Pequeno & $<50$ & $<5$ & Acerola, Buriti, Cacho-de ouro, Cumaru, Ginja ou Pitanga, \\
\cline { 3 - 4 } & & $>5$ & $\begin{array}{l}\text { Murta de jardim, Muruci, Oiti, Pitomba, Pupunha, Taperebá } \\
\text { Laranja, Limão, Manu ou cajuí da mata, Castanhola, Côco, Goiaba, Ingá- cipó, Jambo, }\end{array}$ \\
\hline Grande & $>50$ & $>5$ & \\
\hline
\end{tabular}

Durante a escolha das espécies é preciso considerar a possíveis quedas de frutos de tamanhos grandes e pesados como a Ata, Caju, Cajuaçu, Côco, Goiaba, Ingá-cipó, Jambo, Laranja e Manga que, de acordo com Toscan et al. (2010), podem provocar danos a pedestres e veículos, além de causar sujeira e atrair vetores de doenças. Desta forma, recomenda-se o plantio desses indivíduos pode ocorrer desde que não seja em áreas destinadas à convivência humana onde haverá o trafego de pessoas nas proximidades das árvores.

\section{CONCLUSÕES}

Na composição arbórea da silvicultura urbana de Santarém 40,09\% dos indivíduos são espécies frutíferas alimentares para a população e avifauna local, onde há predomínio da população exótica com destaque à Mangifera indica L. Além disso, é possível afirmar que espécies com frutos grandes e pesados podem ser utilizadas desde que haja planejamento e manutenção nos ambientes em que serão introduzidas.

\section{REFERÊNCIAS}

LOUREIRO, V. R.; BARBOSA, E. J. S.. Cidade de Belém e natureza: uma relação problemática?. Revista Novos Cadernos, v.13, n.1, 2011

BASSO, J. M.; CORREA, R. S.. Arborização urbana e qualificação da paisagem. Paisagem e Ambiente: Ensaios, n.34, p.129-148, 2014.

BIONDI, D.; PEDROSA MACEDO, J. H. P.. Plantas invasoras encontradas na área urbana de Curitiba (PR). Revista Floresta, Curitiba, v.38, n.1, p.129-144, 2008.

BOYLE, B.; HOPKINS, N.; LU, Z.; GARAY, J. A. R.; MOZZHERIN, D.; REES, T.; MATASCI, N.; NARRO, M. L.; PIEL, W. H.; MCKAY, S. J.; SONYA, L. .; CHRIS, F.; P., R. K.; BRIAN, J. E.. The taxonomic name resolution service: an online tool for automated standardization of plant names. BMC bioinformatics, v.14, n.1, p.16, 2013.

BYNG, J. W.; CHASE, M. W.; CHRISTENHUSZ, M. J. M.; FAY, M. F.; JUDD, W. S.; MABBERLEY, D. J.; SENNIKOV, A. N.; SOLTIS, D. E.; SOLTIS, P. S.; STEVENS, P. F.; BRIGGS, B.; BROCKINGTON, S.; CHAUTEMS, A.; CLARK, J. C.; CONRAN, J.; HASTON, E.; MOLLER, M.; MOORE, M. J.; OLMSTEAD, R. G.; et al. An update of the Angiosperm Phylogeny Group classification for the orders and families of flowering plants:
APG IV. Botanical Journal of the Linnean Society, v.181, n.1, p.1-20, 2016

CARVALHO, J. A.; NUCCI, J. C.; VALASKI, S.. Inventário das árvores presentes na arborização de calçadas da porção central do bairro Santa Felicidade, Curitiba/PR. Revista da Sociedade Brasileira de Arborização Urbana, Piracicaba, v.5, n.1, p.126-143, 2010.

CASTRO, H. S.; DIAS, T. C. A. C.. Percepção Ambiental e Arborização Urbana em Macapá, Amapá. Revista Biota Amazônia, v.3, n.3, p.34-44, 2013.

CEMIG. Companhia Energética de Minas Gerais. Manual para Elaboração do Plano Municipal de Arborização Urbana. São Paulo: Embrapa, 2011.

LIRA FILHO, J. A.; MEDEIROS, M. A. S.. Impactos adversos na avifauna causados pelas atividades de arborização urbana. Revista de Biologia e Ciências da Terra, v.6, p.375-390, 2006.

GOMES, M. A. S.; SOARES, B. R.. A Vegetação nos Centros Urbanos: considerações sobre os espaços verdes em cidades médias brasileiras. Estudos Geográficos, Rio Claro, v.1, n.1, p.19-29, 2003. 
IBGE. Instituto Brasileiro de Geografia e Estatística. Brasil em Síntese. Brasília: IBGE, 2019.

LORENZI, H.. Árvores Brasileiras: Manual de Identificação e Cultivo de Plantas Arbóreas do Brasil. 4 ed. São Paulo: Instituto Plantarum, 2002.

LORENZI, H.; SOUZA, H. M.. Plantas ornamentais no Brasil: arbustivas, herbáceas e trepadeiras. 3 ed. São Paulo: Instituto Plantarum, 2001

MELO, R. R.; LIRA FILHO, J. A.; RODOLFO JÚNIOR, F.. Diagnóstico qualitativo e quantitativo da arborização urbana no bairro Bivar Olinto, Patos, Paraíba. Revista da Sociedade Brasileira de Arborização Urbana, Piracicaba, v.2, n.1, p.6478, 2007.

NASCIMENTO, J. F.; GUEDES, J. A.. Arborização urbana no espaço público de Major Sales, RN. Caderno de Estudos Geoambientais, v.6, n.1, p.17-31, 2015.

OLIVEIRA, M.; FERREIRA, A.; LOPES, R. S.; REIS, R.; JUNIOR, J. S.; AMARAL, J. C.. Espécies vegetais presentes em praças e avenidas do município de Aldeias Altas, Maranhão, Brasil. Revista Sociedade Brasileira de Arborização Urbana, Piracicaba, n.12, p.13-22, 2017.

PAIVA, A. V.; LIMA, A. B. M.; CARVALHO, A.; et al.. Inventário e diagnóstico da arborização urbana viária de Rio Branco, AC. Revista da Sociedade Brasileira de Arborização Urbana, Piracicaba, v.5, n.1, p.144-159, 2019.

PARRY, M. M.. Composição florística da arborização da cidade de Altamira, Pará. Revista da Sociedade Brasileira de Arborização Urbana, Piracicaba, v.7, n.1, p.143-158, 2019.

PAULA, L.; DUARTE, M. S. S.; TOSTES, R. B.; OLIVEIRA JUNIOR, P. R.; RUBACK, S. S.. Arborização urbana do bairro Centro do município de Cataguases, MG. Revista Agrogeoambiental, Pouso Alegre, v.7, n.2, p.101-112, 2015.

PIRES, N. A. M. T.; MELO, M. S.; OLIVEIRA, D. A.; XAVIERSANTOS, S.. A arborização urbana do município de Goiandira/GO: caracterização qualiquantitativa e proposta de manejo. Revista da Sociedade Brasileira de Arborização Urbana, Piracicaba, v.5, n.3, p.185-205, 2010.
SANTARÉM. Portal da Prefeitura de Santarém. Santarém, 2019.

RIBEIRO, F.. A Arborização urbana em Uberlândia: percepção da população. Revista da Católica, Uberlândia, v.1, n.1, p.224-237, 2009.

RODRIGUES, C. A. G.. Arborização urbana e produção de mudas de essências florestais nativas em Corumbá, MS. Corumbá, 2002.

ROSSATTO, D. R.; TSUBOY, M. S. F.; FREI, F.. Arborização urbana na cidade de Assis-SP: uma abordagem quantitativa. Revista da Sociedade Brasileira de Arborização Urbana, Piracicaba, v.3, n.3, p.1-16, 2008.

SERPA, D. S.; MORAIS, N. A.; MOURA, T. M.. Arborização urbana em três municípios do sul do estado de Goiás: Morrinhos, Goiatuba e Caldas Novas. Revista da Sociedade Brasileira de Arborização Urbana, Piracicaba, v.4, n.3, p.98112, 2019.

SILVA, D. A.; BATISTA, D. B.; BATISTA, A. C.. Percepção da população quanto a arborização com Mangifera indica L.(mangueira) nas ruas de Belém/PA. Revista da Sociedade Brasileira de Arborização Urbana, Piracicaba, v.10, n.1, p.118, 2015.

SILVA, J. G.; PERELLÓ, L. F. C.. Conservação de espécies ameaçadas do Rio Grande do Sul através de seu uso no paisagismo. Revista da Sociedade Brasileira de Arborização Urbana, Piracicaba, v.5, n.4, p.1-21, 2010.

SILVA, L. M.; HASSE, I.; MOCCELIN, R.; ZBORALSKI, A. R.. Arborização de vias públicas e a utilização de espécies exóticas: o caso do bairro Centro de Pato Branco/PR. Revista Scientia Agraria, v.8, n.1, p.47-53, 2007.

STRANGHETTI, V.; SILVA, Z. A. V.. Diagnóstico da arborização das vias públicas do município de Uchôa/SP. Revista da Sociedade Brasileira de Arborização Urbana, Piracicaba, v.5, n.2, p.124-138, 2019.

VELASCO, G. D. N.; LIMA, A. M. L. P.; COUTO, H. T. Z.. Análise comparativa dos custos de diferentes redes de distribuição de energia elétrica no contexto da arborização urbana. Revista Árvore, Viçosa, v.30, n.4, p.679-686, 2006.

A CBPC - Companhia Brasileira de Produção Científica (CNPJ: 11.221.422/0001-03) detém os direitos materiais desta publicação. Os direitos referem-se à publicação do trabalho em qualquer parte do mundo, incluindo os direitos às renovações, expansões e disseminações da contribuição, bem como outros direitos subsidiários. Todos os trabalhos publicados eletronicamente poderão posteriormente ser publicados em coletâneas impressas sob coordenação da Sustenere Publishing, da Companhia Brasileira de Produção Científica e seus parceiros autorizados. Os (as) autores (as) preservam os direitos autorais, mas não têm permissão para a publicação da contribuição em outro meio, impresso ou digital, em português ou em tradução. 